\title{
Deep-fat Frying of Vegetable Oils: Major Chemical Reactions and Effect of Natural Extracts on Oxidative Stability - A Review
}

\author{
T. M. Nanayakkara ${ }^{1,4}$, W.A.G.E. Wijelath ${ }^{2,4^{*}}$ and T.M.M. Marso ${ }^{3,4}$
}

\section{${ }^{1}$ Department of Food Science and Technology, Faculty of Agriculture, University of Peradeniya, Sri Lanka \\ ${ }^{2}$ Department of Animal and Food Sciences, Faculty of Agriculture, Rajarata University of Sri Lanka \\ ${ }^{3}$ Faculty of Education, Horizon Campus, Malabe, Sri Lanka \\ ${ }^{4}$ Postgraduate Institute of Science, University of Peradeniya, Sri Lanka}

\section{Correspondence:}

*wijelath.gihan@gmail.com

iD https://orcid.org/0000-0003-0024-6716

DOI: http://doi.org/10.4038/sljae.v2i2.40

\begin{abstract}
Deep-fat frying is a popular cooking technique in the world and vegetable oil is widely used as the frying medium in this process. Deep-fat frying produces both desirable and undesirable compounds through various chemical reactions. Undesirable chemical compounds are formed mainly through hydrolysis, oxidation and polymerization reactions. These compounds lower the oxidative stability thereby, the quality of oil and food. Antioxidants are added to improve the oxidative stability of oil during deep-fat frying by lowering the free radical action in frying oil. Even though artificial antioxidants are added to frying oils to lower the effects of undesirable chemical reactions and their products, the efficiency of artificial antioxidants decrease with increasing temperature and may cause adverse health effects to the consumer. Natural extracts of rosemary (Rosmarinus officinalis), sage (Salvinia officinalis), tea (Camelia sinensis), oregano (Origanum vulgare) and barley (Hordeum vulgare) are stable under frying conditions and act as effective antioxidants during deep-fat frying. Despite confirmation by numerous research, the use of natural compounds as antioxidants in deep-fat frying is not popular in the food industry. Hence this review explores the major chemical reactions in vegetable oils during deep-fat frying and the effect of natural compounds and extracts in interrupting these undesirable chemical reactions.
\end{abstract}

Keywords: Antioxidants, Deep-fat frying, Natural extracts, Oxidation, Vegetable oil 


\section{Introduction}

One of the most commonly used procedures for preparation and manufacturing of foods throughout the world is deep-fat frying in which the food is subjected to an elevated temperature of $150-190{ }^{\circ} \mathrm{C}$ (Choe and Min 2007). Contact among food, frying oil, and air at high temperatures during deep-fat frying leads to many chemical reactions, thereby affecting the texture, flavour, shelf life, and nutritional quality of both fried food and frying oil in a desirable and undesirable manner (Mohamed et al. 2016).

Hydrolysis, oxidation, and polymerization are common chemical reactions taking place in the oil during deep-fat frying and these reactions produce volatile and non-volatile compounds. Most of these compounds contribute to the changes in the chemical and physical properties of food along with frying oil (Yasahura et al. 2003). Hydrolyzed, oxidized and polymerized products can impart unpleasant odours, flavours, and colours to the food as well as oil (Choe and Min 2007). Furthermore, these reactions limit the re-utilization of oil.

Hence, these undesirable chemical reactions need to be controlled. Antioxidants can be added to frying oils to prevent or slow down the chemical reactions during deep-fat frying by controlling free radical action (Che and Tan 1999).

Synthetic antioxidants such as propyl gallate (PG), butylated hydroxyanisole (BHA), butylated hydroxytoluene (BHT), and tertiary butylhydroquinone (TBHQ) are used to slow down the oxidation of vegetable oils at room temperature. However, their efficiency is low at frying conditions due to losses through decomposition and volatilization at temperatures above $150{ }^{\circ} \mathrm{C}$ (Choe and Lee 1998). Antioxidant activity of natural additives such as extracts of rosemary (Rosmarinus officinalis), tea (Camellia sinensis), sage (Salvinia officinalis), oregano (Origanum vulgare) and barley seeds (Hordeum vulgare) is high at frying conditions, thus these plant extracts are effective in slowing down the undesirable chemical reactions in oil and food at frying temperatures (Negishi et al. 2003). Hence, the addition of natural antioxidants can improve the stability of frying oils (Sharif et al. 2009). Moreover, natural antioxidants are safer and provide additional health benefits compared to synthetic antioxidants because degradative products of synthetic antioxidants exhibit potential carcinogenic and mutagenic properties (Nor et al. 2008).

Vegetable oils are commonly used in deep-fat frying. The application of natural compounds as 
antioxidants in deep-fat frying is limited. Thus, this review focuses on major chemical reactions and the effects of adding natural extracts and compounds to vegetable oils during the deep-fat frying process.

\section{Vegetable oils}

Vegetable oils have a plant origin and are referred to as plant oils in the liquid state at ambient conditions (Hammond 2003). They are extracted from oil containing seed, fruit, or nut tissues of plants by different extraction methods such as solvent extraction, expelling, or combination of these (Bennion 1995). In some instances, vegetable oils are subjected to physical or chemical refining processes to enhance sensory properties (Mohomed et al. 2016).

Edible vegetable oils are principally composed of a complex mixture of triglycerides and may contain fewer amounts of other lipids such as phospholipids, free fatty acid (FFA), sterols, and glycolipids (CODEX Standards 210, 1999). Further, these triglycerides are characterized by attached fatty acid fragments with different chain lengths and unsaturation (Hammond 2003).
Popular vegetable oils in edible use entail coconut (Cocos nucifera) oil, palm (Elaeis guineensis) kernel, and mesocarp oils, sunflower (Helianthus annuus) oil, soybean (Glycine max) oil, cottonseed (Gossypium herbaceum) oil, and peanut (Arachis hypogeae) oil. Among them, palm oil or palm mesocarp oil is the highest consumed vegetable oil in the world (Sanders 2016). Tables 1 and 2 show names of different fatty acid fragments present in triglycerides and a general fatty acid profile of common edible vegetable oils, respectively.

Vegetable oils have a variety of food and nonfood uses. Food uses include cooking, production of margarine, shortening, and compound fat while non-food uses include use as biofuels, production of soaps, detergents, paint, varnish, resin, plastic, and lubricants depending on the chemical and physical properties of vegetable oils (Aluyor and OriJesu 2008). Among a variety of food and nonfood uses of vegetable oils, this review mainly focuses on the chemical reactions in vegetable oils during deep-fat frying and the applicability of natural extracts to improve the oxidative stability of the frying oil. 
Table 1: Names (systematic and trivial) and lipid numbers of selected fatty acids

\begin{tabular}{lll}
\hline Systematic Name & Trivial Name & Lipid Number \\
\hline Octanoic acid & Caprylic acid & C8:0 \\
Decanoic acid & Capric acid & C10:0 \\
Dodecanoic acid & Lauric acid & $\mathrm{C} 12: 0$ \\
Tetradecanoic acid & Myristic acid & $\mathrm{C} 14: 0$ \\
Hexadecanoic acid & Palmitic acid & $\mathrm{C} 16: 0$ \\
(Z)-Hexadec-9-enoic acid & Palmitoleic acid & $\mathrm{C} 16: 1$ \\
Octadecanoic acid & Stearic acid & $\mathrm{C} 18: 0$ \\
(E)-Octadec-9-enoic acid & Elaidic acid & $\mathrm{C} 18: 1 \mathrm{n} 9 \mathrm{t}$ \\
(Z)-Octadec-9-enoic acid & Oleic acid & $\mathrm{C} 18: 1 \mathrm{n} 9 \mathrm{c}$ \\
(9E,12E)-Octadeca-9,12-dienoic acid & Linolelaidic acid & $\mathrm{C} 18: 2 \mathrm{n} 6 \mathrm{t}$ \\
(9Z,12Z)- Octadeca-9,12-dienoic acid & Linoleic acid & $\mathrm{C} 18: 2 \mathrm{n} 6 \mathrm{c}$ \\
all-cis-6,9,12-octadecatrienoic acid & $\gamma$-Linolenic acid & $\mathrm{C} 18: 3 \mathrm{n} 6$ \\
all-cis-9,12,15-octadecatrienoic acid & $\alpha$-Linolenic acid & $\mathrm{C} 18: 3 \mathrm{n} 3$ \\
Eicosanoic acid & Arachidic acid & $\mathrm{C} 20: 0$ \\
(Z)-Eicos-11-enoic acid & Gondoic acid & $\mathrm{C} 20: 1 \mathrm{n} 9$ \\
Docosanoic acid & Behenic acid & $\mathrm{C} 22: 0$ \\
\hline
\end{tabular}

(Source: Hammond 2003)

Table 2: Fatty acid composition of commonly utilized vegetable oils

\section{Vegetable $\quad$ Fatty Acid (\%)}

$\begin{array}{llllllllllllll}\text { Oil } & 8: 0 & 10: 0 & 12: 0 & 14: 0 & 16: 0 & 16: 1 & 18: 0 & 18: 1 & 18: 2 & 18: 3 & 20: 0 & 20: 1 & 22: 0\end{array}$

\begin{tabular}{lccccccccccccc}
\hline Coconut & 8.1 & 6.5 & 48.6 & 17.7 & 8.5 & & 2.5 & 6.5 & 1.5 & & 0.1 & & \\
Palm kernel & 4.0 & 4.1 & 49.7 & 16.0 & 8.0 & & 2.4 & 13.7 & 2.0 & & 0.1 & \\
Palm mesocarp & & & 1.0 & 43.8 & 0.5 & 5.0 & 38.5 & 10.5 & 0.3 & 0.4 & \\
Sunflower & & 0.1 & 0.2 & 6.8 & 0.1 & 4.7 & 18.6 & 68.6 & 0.5 & 0.4 & \\
Soybean & & & & 10.0 & 0.2 & 3.5 & 21.0 & 55.3 & 9.2 & 0.5 & & 0.3 \\
Cottonseed & & & 1.0 & 23.9 & 0.5 & 2.9 & 18.5 & 52.5 & 0.3 & 0.4 & \\
Peanut & & & & 10.1 & 0.2 & 3.5 & 51.4 & 27.3 & 0.1 & 1.6 & 1.3 & 3.1 \\
\hline
\end{tabular}

(Source: Hammond 2003) 


\section{Major chemical reactions in deep-fat frying of vegetable oils}

Deep fat-frying is a cooking process in which, the oil is subjected to high temperatures allowing simultaneous heat and mass transfer between oil and food material. During the process, food materials are quickly heated and cooked when they are immersed in the oil since oil is a first-class heat transfer medium (Alvis et al. 2009). The mass transfer involves the loss of some macro constituents in food such as moisture from fried material to the frying oil and oil uptake of fried material from the frying oil. However, deep-fat frying has an insignificant impact on other macro constituents such as protein and carbohydrate content of fried material (Fillion and Henry 1998). Frying of food in heated oil causes moisture to form steam and evaporate with bubbling. Water, steam, and oxygen initiate the chemical reactions in both frying oil and food.

Consequently, both fried material and frying oil influence one another and conjointly promote the incidence of advanced chemical reactions in the oil during frying: mainly hydrolysis, oxidation, and polymerization (Choe and Min 2007).

\section{Triglyceride hydrolysis}

In hydrolysis, the lipid molecule is broken into two fragments by an external nucleophilic molecule, water. In here, only saponifiable lipids undergo hydrolysis and in vegetable oil mainly triglyceride undergoes hydrolysis as it is the main lipid constituent (Dauqan et al. 2011).

During a complete hydrolysis reaction (Fig. 1), free fatty acids and glycerol are produced when water strikes the ester linkage of triglyceride whereas, partial hydrolysis yields monoacylglycerols and diacylglycerols. Furthermore, the reaction is possible under ambient conditions once moisture contacts with the lipid molecule (Omer et al. 2014) and is accelerated during deep-frying as heat energy promotes any chemical reaction (Nawar 2007).

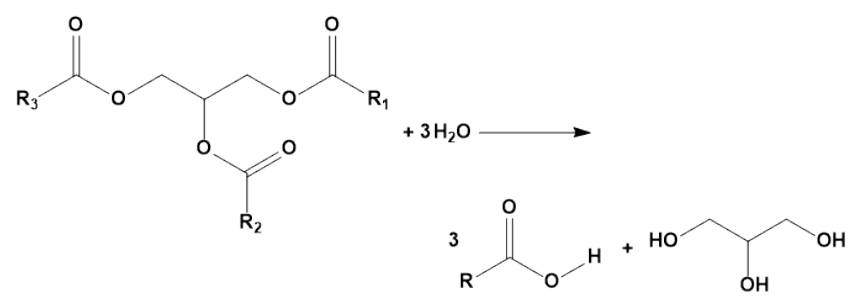

Figure 1: Triglyceride hydrolysis reaction (Source: adapted from Clayden et al. 2012)

Acidic and basic conditions catalyze the hydrolysis reaction. Mechanisms under each acidic and basic condition are shown in Fig. 2.a and $b$, respectively. In there, the base-catalyzed 
hydrolysis is faster than acid-catalyzed hydrolysis (Farhoosh and Kenari 2009).

Chung et al (2010) showed that the amount of free fatty acids in the frying oil increases with repeated frying which is the reason for not recommending repeated frying of the same oil. Additionally, free fatty acids and other hydrolyzed products also speed up further hydrolysis reactions of oil (Frega et al. 1999).

Water from food is easily accessible to frying oils for hydrolysis (Omer et al. 2014). Free fatty acids and their oxidized compounds produce substandard rancid flavour and make the oil unsuitable for deep-fat frying (Hidalgo 2015).

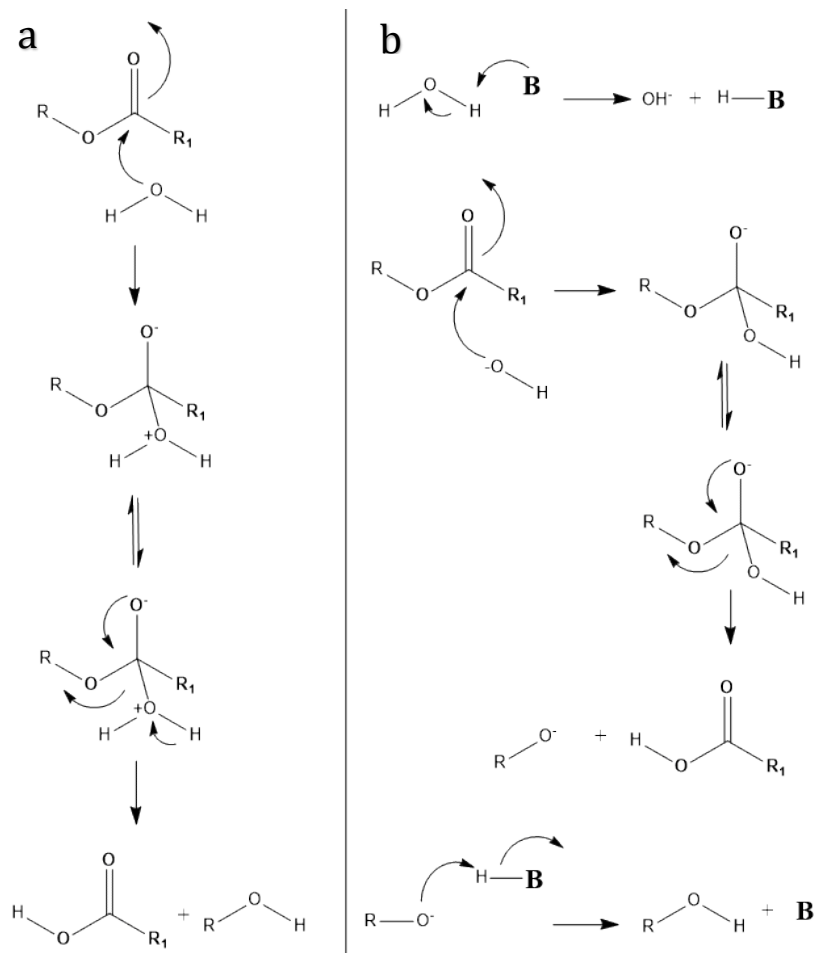

Figure 2: Triglyceride hydrolysis mechanism under a (acid-catalyzed) and b (base-catalyzed) conditions (Source: adapted from Clayden et al. 2012)

\section{Oil oxidation}

Oxidation is the most prominent chemical reaction in deep-fat frying and it is a complex process initiated by the action of free radicals at the double bonds of the unsaturated fatty acid chain (Warner et al. 1994). Therefore, susceptibility to oxidation and the rate of oxidation is increased with the degree of unsaturation of the fatty acid chain (Choe and Min 2007).

Similar to other free radical reactions, oxidation of oil is associated with three main steps: initiation, propagation, and termination (Houhoula et al. 2003). The initiation phase involves the step which originally forms a radical. The hydrogen proton with the most uncertain bond on the carbon chain is removed initially to turn into radical called alkyl radicals (Choe and Min 2005). These alkyl radicals can react with diradical oxygen and create more radicals hence, propagate free radical chain reaction. Alkoxy radicals are formed since most of the radicals formed during the process are not stable at elevated temperatures and the alkoxy radicals rebound with other alkoxy radicals or break down into non-radical products (Choe and Min 2005).

According to the mechanism, as shown in Fig. 3, double bonds present in the fatty acid chain can undergo oxidation when in contact with oxygen 
and form hydroperoxide and peroxide radicals as primary oxidative products (Houhoula et al. 2003). The resulting primary oxidative products lead to the formation of secondary oxidative products such as aldehydes and ketones, which often produce distinctive and generally undesirable rancid flavours (Marmesat et al. 2010). Furthermore, the accumulation of these components over time increases the tendency of the product to be rejected (Choe and Min 2007).

The process of oxidation is affected by many factors including atmospheric oxygen, frying temperature, metals, exposure to light, and other chemical components that promote the initiation of the oxidation process by forming free radicals (Omer et al. 2014).

Step 01 - Hydroperoxide formation

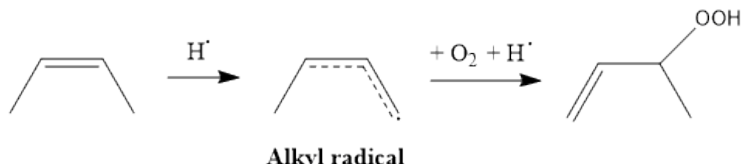

Step 02 - Hydroperoxide decomposition

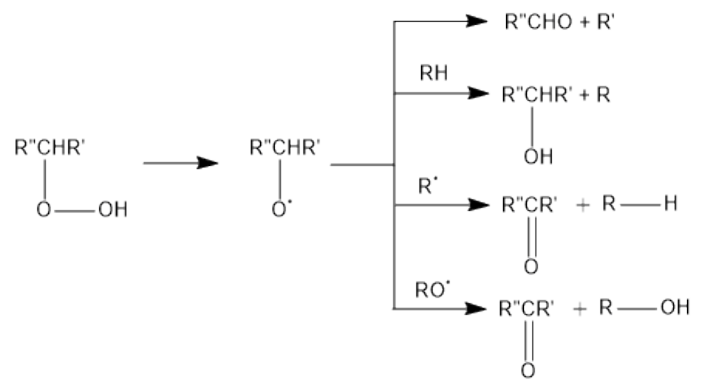

Figure 3: Fatty acid oxidation mechanism

(Source: adapted from Clayden et al. 2012)

\section{Oil polymerization}

Polymerization in deep-fat frying is a radical reaction and involves addition polymerization of fatty acid chains (Omer et al. 2014). In here, unsaturated fatty acids (monomers) undergo successive addition to one another forming a polymer chain (Choe and Min 2007). The reaction is occurred by way of radical intermediates.

Polymerization of oil during deep-fat frying depends on the type of oil, frying temperature, and, number of frying cycles. With an increase in the number of frying cycles and the frying temperature, the amounts of polymers increase (Cuesta et al. 1993). Polymerized compounds formed during deep-fat frying are well supplied with oxygen and these compounds stimulate oxidation of oils, thus resulting in additional degradation (Yoon et al. 1988). Further, foods rich in carbohydrates and amino acids can produce acrylamide in the deep-fat frying process and the formed acrylamide can undergo condensation polymerization to form acrylic polymers (Becalski et al. 2003; Zyzak et al. 2003). Acrylamides and its polymers show potential carcinogenic activity (Gertz and Klostermann 2002). Polymers provoke oil uptake to food materials and reduce the oil quality by developing off colours, raising the viscosity, producing foam in frying medium, 
and lowering the heat transfer rate (Tseng et al. 1996).

\section{Oil quality and factors affecting oil quality during deep-fat frying}

Vegetable oil quality refers to the inherent characteristic of oil including physical, chemical, and nutritional aspects that shall ensure the safety of the oil for consumption (Kochhar and Gertz 2000). Although there is no official set of standards for assessing edible vegetable oil quality, acid value, peroxide value, and $\mathrm{p}$-anisidine value are generally used as quality parameters to determine the oil quality (Oklahoma State University 2016). These fundamental quality parameters and their recommended levels are shown in Table 3. Moreover, fatty acid profile determines the fatty acids composition of vegetable oils and can be used to assess the degree of unsaturation and length of the carbon chain of fatty acids hence the type of fatty acids in vegetable oils (Knothe and Kenar 2004).

Free fatty acids are mainly produced during the hydrolysis of triglyceride and it increases the acid value of vegetable oil. Peroxide value is a measure of primary oxidative products while $p$ anisidine value is a measure of secondary oxidative products. These oxidative products are produced during the process of oil oxidation and polymerization (Zhang et al. 2012).

Quality of vegetable oils alters upon subjection to deep-fat frying. Many external and internal factors affect the quality of vegetable oils used for deep-fat frying. Among the external factors include frying time and temperature, the number of frying cycles, the composition of food to be fried, type of fryer, and antioxidants while internal factors include composition and dissolved oxygen content of oil (Xua et al. 1999; Choe and Min 2007).

High frying temperature and time fasten the oxidation and polymerization of vegetable oils (Fedeli 1988; Blumenthal 1991). Tyagi and Vasishtha (1996) revealed that deep-fat frying at temperatures of $190{ }^{\circ} \mathrm{C}$ compared with 170 ${ }^{\circ} \mathrm{C}$ resulted in a higher amount of decomposed products, increased colour, viscosity, and free fatty acids due to accelerated hydrolysis, oxidation, and polymerization.

An increase in the number of frying cycles decrease triglyceride content and increase polar compounds such as short-chain polymerized compounds and free fatty acids (Mazza and Qi 1992; Gordon and Kourimski 1995; Tompkins and Perkins 2000). Accumulation of these products lowers the nutritive value and sensory appealing of the 
vegetable oils (Romero et al. 1998). Additionally, free fatty acids in frying oil can accelerate the thermal oxidation of oils (Miyashita and Takagi 1986; Mistry and Min 1987; Frega et al. 1999).

Even though saturated fatty acids provide greater stability in deep-fat frying, they may cause adverse health effects to the consumer (Sanibal and Mancini 2004; Dauqan et al. 2011). However, unsaturated fatty acids are more susceptible to hydrolysis, oxidation, and polymerization reactions and they tend to convert the cis form into transform during the process (Frega et al. 1999). Trans fats exhibit proven negative consequences including obesity, cardiovascular diseases, and cancers (Frega et al. 1999). Thus, coconut and olive oils which consist of less unsaturated fatty acids can be considered better vegetable oils for deep-fat frying than soybean, palm, and canola (Brassica napus) oils with more unsaturated fatty acids (Warner and Nelsen 1996).

Table 1: Oil quality parameters and their recommended levels in edible vegetable oils

\begin{tabular}{|c|c|c|c|c|}
\hline \multirow[t]{2}{*}{ Quality Parameter } & \multirow[t]{2}{*}{ Definition } & \multicolumn{2}{|c|}{ Recommended Level } & \multirow[t]{2}{*}{ Reference } \\
\hline & & $\begin{array}{l}\text { Refined } \\
\text { Oils }\end{array}$ & $\begin{array}{l}\text { Cold Pressed and } \\
\text { Virgin Oils }\end{array}$ & \\
\hline $\begin{array}{l}\text { Acid Value (AV) } \\
(\mathrm{mg} \mathrm{KOH} / \mathrm{g})\end{array}$ & $\begin{array}{l}\text { Amount of } \mathrm{KOH} \\
\text { (mg) required to } \\
\text { neutralize acid } \\
\text { components } \\
\text { present in 1g of oil }\end{array}$ & 0.6 & 4.0 & $\begin{array}{l}\text { CODEX STAN } 210 \\
\text { (1999) }\end{array}$ \\
\hline $\begin{array}{l}\text { Peroxide Value (PV) } \\
\text { (milliequivalents of } \\
\text { active oxygen } / \mathrm{kg} \text { oil) }\end{array}$ & $\begin{array}{l}\text { Amount of } \\
\text { peroxide oxygen } \\
\text { per } 1 \mathrm{~kg} \text { of oil }\end{array}$ & Up to 10 & Up to 15 & $\begin{array}{l}\text { CODEX STAN } 210 \\
(1999)\end{array}$ \\
\hline $\begin{array}{l}\text { P-Anisidine Value } \\
\text { (AnV) }\end{array}$ & $\begin{array}{l}\text { Amount of } \\
\text { secondary } \\
\text { oxidative products } \\
\text { in oil }\end{array}$ & Up to 6 & Up to 8 & $\begin{array}{l}\text { CODEX STAN } 210 \\
\text { (1999), Shahidi and } \\
\text { Zhong (2005) }\end{array}$ \\
\hline
\end{tabular}

Note: These quality parameters may change depending on the type of vegetable oil and the processing mechanism

Dissolved oxygen in oil facilitates chemical reactions by assisting in the formation of reactive oxygen species and free radicals (Omer et al. 2014). Dissolved oxygen content in frying oils can be decreased by nitrogen or carbon dioxide flushing thereby reducing the oxidation 
of oil during deep-fat frying. Carbon dioxide flushing is more efficient than nitrogen flushing since carbon dioxide has a comparatively higher density and solubility than nitrogen (Przybylski and Eskin 1988).

When considering the effect of the composition of food, oil hydrolysis increases with the moisture content of the food. On the contrary, the presence of transition metals in food: particularly those possessing two or more valence states with a suitable redox potential between them can act as major pro-oxidants (Blumenthal and Stier 1991). Artz et al. (2005) showed that the transition metals present in meat products can get accumulated in oil during deep-fat frying and this can lead to an increase in the rate of oxidation in vegetable oils.

A small surface to volume ratio of the fryer for minimum contact of oil with air is recommended for deep-fat frying as the type of fryer affects the frying oil quality (Negishi et al. 2003).

\section{Oxidative stability of vegetable oils during deep-fat frying}

Oxidative stability sometimes referred to as the induction period, is the time during which the oil naturally resists the oxidation (Frankel 1998). Oxidative stability of oils is one of the vital parameters in the quality assessment of frying oils (Madhujith and Sivakanthan 2018). Frying oil must have high oxidative stability when using as the frying medium (Marinova et al. 2012). High oxidative stability shows the perseverance against the oxidation of vegetable oils to enhance food applications and minimize the formation of undesirable oxidative products (Madhujith and Sivakanthan 2018).

The application of synthetic and natural antioxidants to the frying medium has been extensively studied to optimize the oxidative stability of vegetable oils during deep-fat frying (Marmesat et al. 2010).

\section{Effect of antioxidants on the oxidative stability of vegetable oils}

By general definition, an antioxidant is a molecule capable of decelerating or preventing the oxidation of other species in a particular medium which are readily oxidizable (Che Man and Tan 1999). Furthermore, it is also referred to as any type of chemical agent which inhibits attack by oxygen or ozone (Marmesat et al. 2010). Oxidative stress occurs when this critical balance is disrupted due to depletion of antioxidants or excess accumulation of reactive oxygen species or both (Scandalios 2005).

Vegetable oils contain a range of components such as vitamin $\mathrm{E}$ and its derivatives (tocopherol, tocotrienol), triacylglycerols, 
polyphenols, sterols, carotenoids act as natural antioxidants which are beneficial to enhance oxidative stability (Ali et al. 2016). The most common naturally occurring antioxidants in vegetable oils are tocopherols and tocotrienols (Dauqan et al. 2011) as shown in Fig. 4. They are further classified as $\alpha, \beta, \gamma$ and $\delta$ depend on the methyl substitutions in the aromatic ring as stated in Table 4. These phenolic compounds protect vegetable oils from immediate oxidation and enhance oxidative stability by
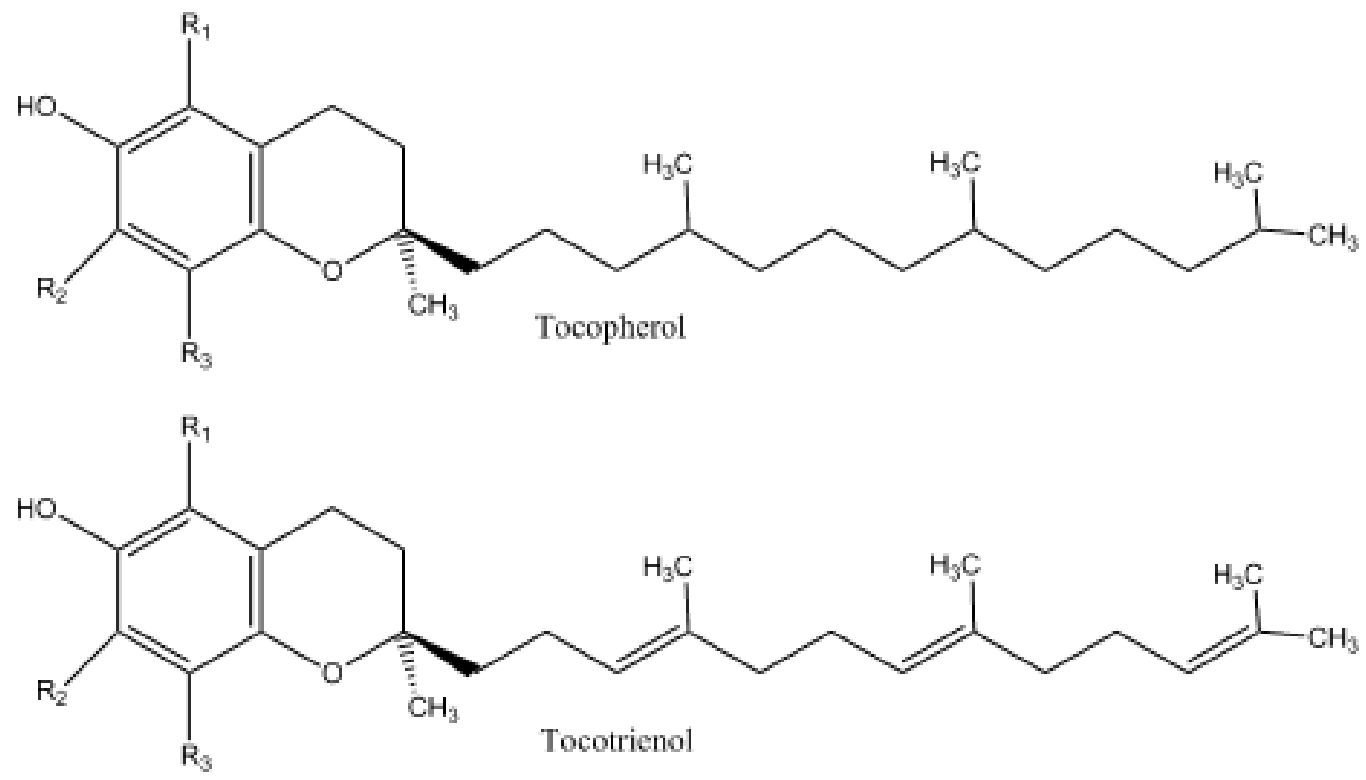

Figure 4: Tocopherol and Tocotrienol structure $\left(R_{1}, R_{2}\right.$ and $R_{3}$ are specified in Table 4$)$ (Source: Setiadi et al. 2003)

Table 4: Methyl substitutions in tocopherol and tocotrienol families

\begin{tabular}{llll}
\hline Type & $\mathbf{R}_{1}$ & $\mathbf{R}_{2}$ & $\mathbf{R}_{3}$ \\
\hline $\boldsymbol{\alpha}$ & $\mathrm{CH}_{3}$ & $\mathrm{CH}_{3}$ & $\mathrm{CH}_{3}$ \\
$\boldsymbol{\beta}$ & $\mathrm{CH}_{3}$ & $\mathrm{H}$ & $\mathrm{CH}_{3}$ \\
$\boldsymbol{\gamma}$ & $\mathrm{H}$ & $\mathrm{CH}_{3}$ & $\mathrm{CH}_{3}$ \\
$\boldsymbol{\delta}$ & $\mathrm{H}$ & $\mathrm{H}$ & $\mathrm{CH}_{3}$ \\
\hline
\end{tabular}

(Source: Setiadi et al. 2003) scavenging free radicals (Patterson 1989). However, commonly consuming edible vegetable oils contain these compounds in significantly lower amounts and some of them can be lost at frying temperatures (Choe and Min 2007). Thereby, the addition of antioxidants in the deep-fat frying process has been taken into consideration. 
synthetic antioxidants under frying conditions is very rapid and their activity is relatively low at elevated temperatures above $180 \mathrm{C}^{\circ}$ (Che Man and Tan 1999). Moreover, recent studies have elaborated that synthetic antioxidants can be degraded into potentially toxic elements upon exposure to high frying temperatures (Mermesat et al. 2010). Farag et al. (2003) have shown that BHT induced severe damage to the rat kidney and lungs at $200 \mathrm{ppm}$ level. Thus, the use of synthetic antioxidants in the deep-fat frying process can lead to concerns in food quality and safety.

\section{Natural extracts added to vegetable oil}

Extracts of rosemary (Gordon and Kourimska, 1995; Jaswir et al. 2000 a), sage (Jaswir et al. 2000 a), tea (Naz et al. 2005), barley seeds, and oregano (Houhoula et al. 2003) contain potential antioxidants with effectiveness similar to that of synthetic antioxidants such as BHA and BHT. Kim et al (1994) stated that many plant extracts including herbs, spices, tea, cocoa bean (Theobroma cacao) shells, rose hips (Rosa canina), coffee beans (Coffea spp.), sesame (Sesamum indicum) oil, tomato (Solanum Lycoperisicum), olive (Olea europaea) leaves, amla fruit (Phyllanthus Emblica), and soybeans (Glycine max) exhibit various degrees of antioxidant activity in different oils.
Rosemary and sage extracts exhibit strong antioxidant characteristics and excellent thermal resistance (Lalas and Dourtoglou 2003). Che Man and Tan (1999) studied the changes in palm oil during deep-fat frying of potato chips using rosemary and sage extracts as antioxidants. Results showed that rosemary and sage extract decrease the deterioration of oil during $30 \mathrm{~h}$ intermittent deep-fat frying of potato chips. Further, it was found that rosemary extract provided better protection to deodorized palm oil against oxidation than BHA, BHT, or even sage extract.

Oxidation of soybean oil using $10 \%$ rosemary extract dissolved in ethanol was lower than when using the maximum legally permitted level of BHA and a similar amount of tocopherol (Normand et al. 2001). Rosemary extract improves the oxidative stability of frying oils and also of oils absorbed into potato chips (Lalas and Dourtoglou 2003). Rosemary extract inhibits Maillard reaction and decreases the development of dark colour in chips during frying due to the control of polymerization reactions (Landers and Rathmann 1981).

Cuvelier et al. (1996) identified 22 compounds in sage and rosemary extracts that have antioxidant properties. They consisted mainly of flavonoids, phenolics, and carnosol derivatives. Carnosol, rosmanol, rosmarinic 
acid, caffeic acid, carnosic acid, and rosmadial were identified as the most effective antioxidants in rosemary extract (Che Man 2000). The antioxidant activity of rosemary extract depends on extraction parameters. Antioxidant properties of rosemary are higher in hexane extract than methanol extract (Che Man 2000). Jaswir et al (2000 b) stated that sage extract, rosemary extract, and citric acid show synergistic antioxidant effects on palm oil during deep-fat frying of potato chips.

Similarly, Nor et al (2008) tested the quality characteristics of refined, bleached, and deodorized (RBD) palm oil during deep-fat frying using pandan (Pandanus Amaryllifolius) leaf extract and BHT as the antioxidant. Oxidation of RBD palm oil during deep-fat frying decreased with an increase in the concentration of pandan leaf extract in oil. Comparison of oil quality indices showed that pandan leaf extract is as effective as BHT (Nor et al. 2008).

Lignan compounds in sesame oil; sesamin, sesamol, and sesamolin are stable during heating and contribute to increased oxidative stability of roasted sesame oil during deep-fat frying (Kim and Choe 2004). Oxidative and flavour stability of sunflower oil is increased by the addition of sesame and rice bran extracts; possibly due to the presence of avenasterol which is stable at high temperature (Kochhar and Gertz 2000). In the same way, the addition of roasted sesame oil to blended oils lowers the formation of conjugated dienoic acids during frying at $160{ }^{\circ} \mathrm{C}$ thereby, lowering the formation of polymerized compounds (Chung and Choe 2001).

Jayasinghe et al (2003) stated that the antioxidant activity of essential oil extracted from basil (Ocimum basilicum) is higher than that of synthetic antioxidant BHT. The essential oil of basil acts as a primary antioxidant due to the presence of flavonoids and phenolic compounds (Hussain et al. 2008). In the same manner, addition of phenolic compounds such as catechin and composites of catechin results in improvement of oxidative stability in peanut oil and palm super oil under deep-fat frying conditions (Razali et al. 2003).

Schroeder et al (2006) showed that carotenes are the major naturally occurring compounds that react with oil radicals in palm oil but they are not protecting oil from thermal degradation in the absence of other antioxidants. Combination of tocotrienols and carotenes lowers the oxidation of oil synergistically during deep-frying of potato slices at $163{ }^{\circ} \mathrm{C}$ through the regeneration of carotene from carotene radicals (Guardiola et al. 2012). 
In the same way, Lee et al $(2002,2003)$ showed that the addition of powders made out of spinach (Spinacia oleracea) and carrot (Daucus carota) to the dough reduced the oxidation of soybean oil during deep-fat frying. Incorporation of red ginseng (Panax Ginceng) extract to flour dough lowers the formation of free fatty acids, conjugated dienoic acids, and aldehydes in palm oil during deep-fat frying of dough at $160^{\circ} \mathrm{C}$ (Kim and Choe 2003).

Consequently, many studies have shown the positive effects of natural extracts and compounds on the oxidative stability and other undesirable chemical reactions of vegetable oils in the deep-fat frying process (Bastida 2001).

\section{Action of natural extracts and compounds} during deep-fat frying

Natural extracts and compounds contain a vast variety of antioxidant phytochemicals including tocopherols, tocotrienols, cathechin, epicathechin, gallic acid, carotenoids, and polyphenols (Zhang et al. 2012). The composition of plant extracts and compounds depends on the variety, solvent used for extraction, concentration added and extraction method (Moure et al. 2001). Antioxidant effect of the compounds varies with frying conditions, degree of unsaturation of oil, content, and chemical structure of minor compounds
(Marmesat et al. 2010). The addition of natural antioxidants enhances oxidative stability during deep-fat frying of vegetable oils.

As applied to vegetable oils, antioxidants are compounds which interrupt the oxidation process by preferentially reacting with the fat radical to form a stable radical which cannot quickly react with oxygen (Jaswir et al. 2000 a). Antioxidants function either by inhibiting the formation of free alkyl radicals in the initiation step or by interrupting the propagation of the free radical chain reaction (Ohio State University 2008). Further, antioxidants can absorb destructive free radical oxygen molecules from oil to slow down the degradation process (Che Man and Tan 1999).

As applied to vegetable oils, antioxidants are compounds which interrupt the oxidation process by preferentially reacting with the fat radical to form a stable radical which cannot quickly react with oxygen (Jaswir et al. 2000 a). Antioxidants function either by inhibiting the formation of free alkyl radicals in the initiation step or by interrupting the propagation of the free radical chain reaction (Ohio State University 2008). Further, antioxidants can absorb destructive free radical oxygen molecules from oil to slow down the degradation process (Che Man and Tan 1999). 
Thereby, the addition of natural antioxidants through plant extracts enhances oxidative stability of vegetable oils by interrupting the oxidation process dominated by undesirable chemical reactions during the deep-fat frying process. Scavenging of free radical actions by antioxidants causes to decline the polymerization and hydrolysis of vegetable oils hence, major chemical reactions during the deep-fat frying process (Aluyor and Ori-Jesu 2008; Normand et al. 2001).

\section{Conclusions}

Deep-fat frying of vegetable oil promotes oxidation, hydrolysis, and polymerization of oil. Compounds produced during these chemical reactions change the stability and quality of frying oil as well as fried food. Alteration of the oil quality during the deep-fat frying mainly depends on factors such as the composition of oil and food, dissolved oxygen content, antioxidants, and other conditions applied (temperature, time, replenishment of oil). Oil quality can be evaluated mainly based on three analytical parameters; acid value, peroxide value, and $p$-anisidine value. The addition of antioxidants to frying oil improves the oxidative stability of oil during deep-fat frying. Antioxidants hinder the oxidation process by inhibiting the formation of free radicals in the initial step or preventing propagation of free radical chain reaction. Synthetic antioxidants improve the stability of oil but become less efficient with increasing temperature. Natural extracts and compounds containing antioxidants are highly effective at elevated temperatures during deep-fat frying. Rosemary, sage, tea, basil, barley, and pandan leaf extracts are stable natural antioxidants under frying conditions and improve oxidative stability and effective against other undesirable chemical reactions taking place during deep-fat frying.

\section{Recommendations}

Majority of the natural extracts and compounds which have been experimentally identified to act as antioxidants during deep-fat frying are not common in Sri Lanka. Studies have shown a wide variety of fruits, vegetables, herbs, spices, and tea available in Sri Lanka have antioxidant properties in their peels, flesh, seeds, and leaves. Some of these perishables have remained underutilized. Further studies should be undertaken to investigate the effect of these fruits, vegetables, and herb extracts and compounds on the quality and safety of commonly used vegetable oils such as coconut oil and palm oil during the deep-fat frying process. 
Conflicts of Interest: The authors declare that there are no conflicts of interest regarding the publication of this paper.

\section{References}

Ali S, Chatha S A S, Ali Q, Hussain A I, Hussain S M Perveen R (2016) Oxidative stability of cooking oil blend stabilized with leaf extract of Eucalyptus citriodora. Int J Food Properties 19(7): 556-1565.

Codex Alimentarius (1999) Codex standard for named vegetable oils, CODEX STAN 2101999. Codex Alimentarius 8: 11-25.

Aluyor E O, Ori-Jesu M (2008) The use of antioxidants in vegetable oils - A review. Afr J Biotech 7(25): 4836-4842.

Alvis A, Velez C, Rada-Mendoza M, Villamiel M, Villada H S (2009) Heat transfer coefficient during deep-fat frying. J Food Control 20: 32325.

Artz W E, Osidacz P C, Coscione A R (2005) Acceleration of the thermosoxidation of oil by heme iron. J American Oil Chemists' Society 82: 579-584.

Bastida S, Sanchez-Muniz F J (2001) Thermal oxidation of olive oil, sunflower oil and a mix of both oils during forty discontinuous domestic frying of different foods. J Food Sci Tech 7: 15-
Becalski A, Lau B P, Lewis D, Seaman S W (2003) Acrylamide in foods: occurrence, sources, and modelling. J Agriculture and Food Chemistry 51: 802-808.

Bennion M (1995) Introductory Foods (10 th Ed). Prentice Hall Inc, New Jersey, USA.

Blumenthal M M, Stier R F (1991) Optimization of deep-fat frying operations - A review. Trends in Food Science and Technology 62: 144-148.

Che Man Y B, Tan C P (1999) Effects of natural and synthetic antioxidants on changes in refined, bleached, and deodorized palm olein during deep-fat frying of potato chips. J American Oil Chemists' Society 76: 331-339.

Che Man Y B (2000) Effect of rosemary and sage extracts on frying performance of refined, bleached and deodorized (RBD) palm olein during deep-fat frying. J Food Chemistry 69: 301-307.

Choe E and Lee J (1998) Thermo-oxidative stability of soybean oil, beef tallow, and palm oil during frying of steamed noodles. Kor J Food Science and Technology 30: 288-292.

Choe E, Min D B (2005) Chemistry and reactions of reactive oxygen species in foods. J Food Science 70: 142-59. 21. 
Choe E, Min D B (2007) Chemistry of deep-fat frying oils. J Food Science.72(5): 77-86.

Chung J, Choe E (2001) Effects of sesame oil on thermo-oxidative stability of soybean oil. J Food Science and Biotechnology 10: 446-450.

Chung, Y K, Bansal G, Zhou W, Barlow P J, Joshi P S, Lo H L (2010) Review of rapid tests available for measuring the quality changes in frying oils and comparison with standard methods. Critical Reviews in Food Science and Nutrition 50(6): 503-514.

Clayden J, Nick G, Stuart W (2012) Organic Chemistry (2 ${ }^{\text {nd }}$ Ed). Oxford University Press, UK 1-1264.

Cuesta C, Sanchez-Muniz F J, Garrido-Polonio C, Lopez-Varela S, Arroyo R (1993) Thermooxidative and hydrolytic changes in sunflower oil used in frying with a fast turnover of fresh oil. J American Oil Chemists' Society 70: 10691073.

Cuvelier M E, Richard H, Berset C (1996) Antioxidative activity and phenolic composition of pilot-plant and commercial extracts of sage and rosemary. J American Oil Chemists' Society 73: 645-652.

Dauqan E M A, Abdullah A, Sani H A (2011) Natural antioxidants, lipid profile, lipid peroxidation, antioxidant enzymes of different vegetable oils. Adv J Food Science and Technology 3(4): 308-316.

Farag R S, El-Baroty G S, Basuny A (2003) Safety evaluation of olive phenolic compounds as natural antioxidants. Int J Food Sciences and Nutrition 54(3): 159-174.

Farhoosh R, Kenari R E (2009) Anti-rancidity effects of sesame and rice bran oils on canola oil deep frying. J American Oil Chemists' Society 86: 539-544.

Fedeli E (1988) The behaviour of olive oil during cooking and frying. In: Varela G, Bender A E, Morton I D (Eds) Frying of Food: Principles, Changes, New Approaches. VCH Publishers, New York, USA 52-81.

Fillion L and Henry C J K (1998) Nutrient losses and gains during frying: a review. Int J Food Sciences and Nutrition 49(2): 157-168.

Frankel E N (1998) Oxidative stability. In: Dundee N (Ed) Lipid oxidation. The Oily Press, Scotland 68-75.

Frega N, Mozzona M, Lerckerb G (1999) Effects of free fatty acids on oxidative stability of vegetable oil. J American Oil Chemists' Society 76: 325-329.

Gertz, C, Klostermann S (2002) Analysis of acrylamide and mechanisms of its formation in 
deep-fried products. Eur J Lipid Science and Technology 104: 762-771.

Gordon M H, Kourimska L (1995) The effects of antioxidants on changes in oils during heating and deep frying. J Agricultural and Food Chemistry 68: 347-353.

Guardiola F, Codony R, Tres A, Navas J A, Bou R (2012) Quality assessment of frying fats and fried snacks during continuous deep-fat frying at different large-scale producers. J Food Control 27: 254-267.

Hammond E W (2003) Vegetable oils: Types and properties (2 ${ }^{\text {nd }}$ Ed). Academic Press, USA 5899-5904.

Hidalgo F J, Zamora R, Navarro J L, Aguilar I (2015) Lipid-derived aldehyde degradation under thermal conditions. J Food Chemistry 174: 89-96.

Houhoula D P, Oreopoulou V, Tzia C (2003) The effect of process time and temperature on the on the accumulation of polar compounds in cotton seed oil during deep-fat frying. J Science Food and Agriculture 83: 314-319.

Hussain A I, Anwar F, Sherazi S T H, Przybylski R (2008) Chemical composition, antioxidant and antimicrobial activities of basil (Ocimum basilicum) essential oils depends on seasonal variations. Food chemistry 108(3): 986-995.
Jaswir I, Che Man Y B, Kitts D D (2000 a) Synergistic effects of rosemary, sage, and citric acid on fatty acid retention of palm olein during deep-fat frying. J American Oil Chemists' Society 77: 527-533.

Jaswir I, Che Man Y B, Kitts D D (2000 b) Optimization of phytochemical changes of palm olein with phytochemical antioxidants during deep-fat frying. J American Oil Chemists' Society 77: 1161-1167.

Jayasinghe C, Gotoh N, Aoki T, Wada S (2003) Phenolics composition and antioxidant activity of sweet basil (Ocimum basilicum L.). J Agricultural and Food Chemistry 51(15): 44424449.

Kim I, Choe E (2003) Effects of red ginseng extract added to dough on the lipid oxidation of frying oil and fried dough during frying and storage. Food Science and Biotechnology 12: 67-71.

Kim I, Choe E (2004) Oxidative stability and antioxidant content changes in roasted and bleached sesame oil during heating. Food Science and Biotechnology 13: 762-767.

Kim S Y, Kim J H, Kim S K, Oh M J, Jung M Y (1994) Antioxidant activities of selected oriental herb extracts. J American Oil Chemists' Society 71: 633-640. 
Knothe G, Kenar J A (2004) Determination of fatty acid profile by H'-NMR spectroscopy. Eur J Lipid Science Technology 106: 88-96.

Kochhar S P, Gertz C (2000) Stable and healthful frying oil for the $21^{\text {st }}$ century. J Inform 11: $642-645$.

Lalas S, Dourtoglou V (2003) Use of rosemary extract in preventing oxidation during deep fat frying of potato chips. J American Oil Chemists' Society 80(6): 579-584.

Landers R E, Rathmann D M (1981) Vegetableoil effects of processing, storage and use on nutritional values. J American Oil Chemists' Society 58: 255-259.

Lee J, Kim M, Park K, Choe E (2003) Lipid oxidation and carotenoids content in frying oil and fried dough containing carrot powder. J Food Science 68: 1248-1253.

Lee J, Lee S, Lee H, Park K, Choe E (2002) Spinach (Spinacia oleracea) powder as a natural food-grade antioxidant in deep-fat fried products. J Agricultural and Food Chemistry 50: 5664-5669.

Madhujith T, Sivakanthan S (2018) Oxidative Stability of Edible Plant Oils. In: Mérillon J M, Ramawat K (Eds) Bioactive Molecules in Food. Reference Series in Phytochemistry. Springer, Cham. USA 1-23.
Marmesat S, Morales A, Velasco J, Dobargenes M C (2010) Action and fate of natural and synthetic antioxidants during frying. Grasas Y Aceities 61(4): 333-340.

Marinova E M, Seizova K A, Totseva I R, Panayotova S S, Marekov L N, Momchilova S M (2012) Oxidative changes in some vegetable oils during heating at frying temperature. Bulgarian Chemical Communications 44: 57-63.

Mazza G, Qi H (1992) Effect of after-cooking darkening inhibitors on stability of frying oil and quality of French fries. J American Oil Chemists' Society 69: 847-53.

Mistry B S, Min D B (1987) Effects of fatty acids on the oxidative stability of soy bean oil. J Food Science 52: 831-832.

Miyashita K, Takagi T (1986) Study on the oxidative rate and prooxidant activity of free fatty acids. J American Oil Chemists' Society 63: 1380-1384.

Mohamed A A, Anowar M B, Milad M 0, Omar M A, Alyaa M H (2016) The effects of frying on the thermal behaviour of some vegetable oils. Inter J Agricultural Research and Review 4(7): 529537.

Moure A, Jose M C, Daniel F, Manuel D J, Jorge S, Herminia D, Marõ̂̂A J N, Carlos P J (2001) 
Natural antioxidants from residual sources. J Food Chemistry 72: 145-171.

Nawar W W (2007) Lipids. In: Fennema O R (4th Ed) Food chemistry. Marcel Dekker, Inc., New York, USA 225-320.

Naz S, Siddiqi R, Sheikh H, Sayeed S A (2005) Deterioration of olive, corn, and soybean oils due to air, light, heat, and deep frying. J Food Research International 38: 127-134.

Negishi H, Nishida M, Endo Y, Fujimoto K (2003) Effect of a modified deep-fat fryer on chemical and physical characteristics of frying oil. J American Oil Chemists' Society 80: 163166.

Nor F M, Mohamed S, Idris N A, Ismail R (2008) Antioxidative properties of Pandanus amaryllifolius leaf extracts in accelerated oxidation and deep frying studies. Food Chemistry 110: 319-327.

Normand L, Eskin N A M, Przybylski R (2001) Effect of tocopherols on the frying stability of regular and modified canola oils. J American Oil Chemists' Society 70(4): 369-373.

Ohio State University (2008) Antioxidant [Online]. Available from: http://class.fst.ohiostate.edu. [Accessed on: 12 ${ }^{\text {th }}$ April 2020].
Oklahoma State University (2016) Edible oil quality [Online]. Available from: http://extension.okstate.edu/factsheets/edible-oil-quality.html. [Accessed on: 10 $0^{\text {th }}$ April 2020].

Omer N M A, Ahmed A E M, Mariod A A, Moktar M (2014) Chemical reactions taken place during deep-fat frying and their products: A Review. J Natural Medical Sciences 1: 1-17.

Patterson H B W (1989) Handling and storage of oilseeds: oils, fats and meal. Elsevier Science

Publishers, New York, USA 1-87.

Przybylski R, Eskin N A M (1988) A comparative study on the effectiveness of nitrogen or carbon dioxide flushing in preventing oxidation during the heating of oil. J American Oil Chemists' Society 65: 629-633.

Razali I, Johari M, Nor Aini S (2003) Effects of additives on quality and frying performance of palm super olein during frying. Palm Oil Dev 38: $1-4$.

Romero A, Cuesta C, Sanchez-Muniz F J (1998) Effect of oil replenishment during deep-fat frying of frozen foods in sunflower oil and higholeic acid sunflower oil. J American Oil Chemists' Society 75: 161-167. 
Sanders T H, David J P, Prince K M, Dem L L, Sweigart D S, Cottonario J M (2016) Peanut oil stability and physical properties across a range of industrially relevant oleic acid/linoleic acid ratios. J Peanut Science 43(1): 1-11.

Sanibal E A A, Mancini F J (2004) Frying oil and fat quality measured by chemical, physical, and test kit analyses. J American Oil Chemists' Society 83: 121-127.

Scandalios J G (2005) Oxidative stress: Molecular perception and transduction of signals triggering antioxidant gene defences. Braz J Medicinal Biology and Research 38 (7): 995-1014.

Schroeder M T, Becker E M, Skibsted L H (2006) Molecular mechanism of antioxidant synergism of tocotrienols and carotenoids in palm oil. J Agricultural and Food Chemistry 54: 34453453.

Scott G (1965) Atmospheric oxidation and antioxidants. Elsevier Publishing, Amsterdam, Netherland 335-337.

Setiadi D H, Chass G A, Torday L L, Varro A, Papp J G (2003) Vitamin E models. Shortened sidechain models of $\alpha, \beta, \gamma$ and $\delta$ tocopherol and tocotrienol-a density functional study. J Molecular Structure: Theochem 637(1-3): 1126.
Shahidi F, Zhong Y (2005) Lipid oxidation: measurement methods. Bailey's Industrial Oil and Fat Products. John Wiley \& Sons, Ltd, New Jersey, USA 1-27.

Sharif A, Farhoosh R, Haddad K M H, Tavassoli K M H (2009) Antioxidant activity of Bene hull oil compared with sesame and rice bran oil during the frying process of sunflower oil. J Food Lipids 16: 394-406.

Tompkins C, Perkins E G (2000) Frying performance of low-linolenic acid soybean oil. J American Oil Chemists' Society 77: 223-229.

Tseng Y C, Moreira R G, Sun X (1996) Total frying-use time effects on soybean oil deterioration and on tortilla chip quality. Inter J Food Science and Technology 31: 287-294.

Tyagi V K, Vasishtha A K (1996) Changes in the characteristics and composition of oils during deep-fat frying. J American Oil Chemists' Society 73(4): 499-506.

Warner K, Nelsen T (1996) AOCS collaborative study on sensory and volatile compound analysis of vegetable oils. J American Oil Chemists' Society 73: 157-166.

Warner K, Orr P, Parrott L, Glynn M (1994) Effects of frying oil composition on potato chip stability. J American Oil Chemists' Society 71: 1117-1121. 
Xua X Q, Trana V H, Palmera M, Whiteb K, Salisburyc P (1999) Chemical and physical analyses and sensory evaluation of six deepfrying oils. J American Oil Chemists' Society 76:1091-1099.

Yasahura A, Tanaka Y, Hengel M, Shibamoto T (2003) Gas chromatographic investigation of acrylamide formation in browning model system. J Agricultural and Food Chemistry 51: 3999-4003.

Yoon S H, Jung M Y, Min D B (1988) Effects of thermally oxidized triglycerides on the oxidative stability of soybean oil. J American Oil Chemists' Society 65(10): 1652-1656.
Zhang Q, Saleh A S M, Chen J, Shen Q (2012) Chemical alterations taken place during deepfat frying based on certain reaction products: A review. J Chemistry and Physics of Lipids 165: 662-681.

Zyzak D U, Sanders R A, Marko S, Tallmadge D $\mathrm{H}$ (2003) Acrylamide formation mechanism in heated foods. J agricultural Food Chemistry 51(16): 4782-4787. 